\title{
Empirical Study on the Evaluation System of Physical Education in Regular Colleges and Universities
}

\author{
Nie Jun-wei \\ Jiangxi College Of Foreign Studies
}

\begin{abstract}
With the constantly deeper revolution of physical education as well as update of educational ideas, people have gradually realized that many problems existing in the evaluation practice of physical education are related to current irrational methods, concepts, contents and indicators of physical education evaluation, so revolution in physical education evaluation is in urgent need. In this paper, the author tries to establish a relatively scientific and rational evaluation system suitable for physical education in universities by employing modern pedagogy and psychological theories with analysis on abstract things related to education and people layer by layer; Meanwhile, expert decision method and mathematical statistics are adopted to decompose the evaluation system of physical education into concrete evaluation indicators with empirical study on corresponding prepared evaluation scale.
\end{abstract}

Key words: regular colleges and universities; physical education; evaluation system; empirical study

\section{INTRODUCTION}

The main educational goal of regular colleges and universities for the physical education is to strengthen students' bodies and enhance their health with better physical literacy and stronger ability of life-long exercise so as to cultivate students' good habit of life-long sports and exercise. As for the traditional evaluation on students' physical study, it only paid attention to students' physical and sports skills without

\section{EMERGENCE AND DEVELOPMENT OF THEORIES OF EDUCATIONAL EVALUATION}

Many scholars home and abroad believe that evaluation system originated from ancient China since examination system has had a long history in China since Western Chou dynasty. In ancient China, officers are selected by examinations according to their results. During those studies, American scholars carried out an educational test. With constant development of the test, people had gradually realized that the educational test had some weaknesses and deficiencies. In order to solve much attention to their development of other aspects. Both the evaluation method and standard were simple.

Evaluation on physical education should have offered correct guidance, service and motivation to physical education; however, it has restricted the educational revolution and impeded the implementation of quality education and realization of physical educational goal, which has damaged many students' pride and confidence, affected their activeness in sports learning, and confined their progress and development in physical study. It seems to be objective superficially, but indeed it is unfair for students. Besides, for the teachers' part, evaluation only values teachers' ability of teaching performance while ignores their creativity as well as students' participation in sports activities. The backward evaluation mode of physical education has become one of the problems restricting revolution and development of physical education in colleges and universities, so it is in urgent need to reform the physical education evaluation mode. Therefore, it is of great necessity to establish a evaluation system for physical education in colleges and universities as well as a reliable and operable corresponding evaluation index system so as to truly promote the development of students and teachers. the new problems, Tyler, an American educator, conducted a series experiences, and later he proposed the theories of educational evaluation, which was called "the Tyler mode".

However, the Tyler Mode had been questioned with further study and practice, during which many new evaluation modes came into being. At the early stage of 1980s, Gardner, an American psychologist proposed the theory of multiple intelligence, which had a great effect on educational evaluation. Since then, theory of multiple intelligence has become the thinking basis for plural 
evaluation contents. It reminds people to value students' personalities and unbalanced development with emphasis on each student's unique values. Meanwhile, the theory advocates to establish an individualized evaluation index to promote the realization of individual values. It also offers new ideas for designing students' evaluation methods, such as designing of open questions in teaching and so on, which has provided basis for establishing an evaluation system to promote students' comprehensive development.

III. PROBLEMS EXISTING IN THE EVALUATION SYSTEM OF PHYSICAL EDUCATION IN CHINESE UNIVERSITIES AND COLLEGES

A. As for the evaluation modes and methods, more attention has been paid to the quantity instead of the quality, and the traditional sports results are used to evaluate students' performance without the latest techniques and methods. Besides, the evaluation process is still and closed without dynamics and flexibility.

B. As for the subjects of evaluation, they are usually in a passive position. Although there is some self-evaluation contents, most evaluation comes from the superior levels without much importance to evaluation of the same level or the lower levels.

C. In terms of evaluation result, usually there is only a final conclusive evaluation without periodical evaluations on each stage; besides, the results can 't be reflected scientifically, so it has little effect on promotion and development.
According to the traditional ideas of physical education, one method used to measure the quality of physical education is study of sports skills. Thus, sports results have been put in the highest position; while the main purpose of enhancing mental and physical health as well as strong body can't be realized truly. Under this circumstance, it is impossible for schools to cultivate perfect and sound talents with comprehensive development as well as rich imagination and creativity.

\section{ESTABLISH A EVALUATION SYSTEM FOR THE PHYSICAL EDUCATION IN REGULAR COLLEGES AND UNIVERSITIES}

As the study becomes deeper, more and more scholars believe that the true study is a process that learners learn to construct actively. Therefore, a valuable study takes learners as the main subjects with emphasis on the connection of old knowledge and new knowledge, application and transference of knowledge and skills, process and experience of teaching methods, and important effect of subjects' feelings, attitudes and values during the teaching interaction. Meanwhile, the relationship between humans and education should be understood with people-oriented and development concept, which is the core of current educational concept. That is, teaching methods should be employed according to students' personalities so as to realize comprehensive education and make preparations for life-long study. 
Thus, correspondingly, new evaluation ideas have come into being.

\section{A. Evaluation on physical education has changed} from the single evaluation standard into plural evaluation standards

The current social development requires students not only to possess strong bodies and certain sports skills, but also to have healthy psychology and sound adaptability to society, which needs to change the traditional single evaluation standard for physical education. Thus, the evaluation system for physical education is surely becoming diversified, which can greatly improve the reliability and validity of evaluation results, and it can also better give play to the motivation function of evaluation.

\section{B. PE teachers are allowed to formulate corresponding evaluation standards according to their practical teaching.}

In different regions, students of different genders and different ages may have differences in physical abilities and sports skills. Even in the same region and the same school, students of the same age and the same gender may have different physical abilities and sports skills in different stages.

\section{CONCLUSION}

In this paper, the evaluation system for physical education in colleges and universities established according to theoretical research methods is basically consistent with the educational evaluation concepts of promoting students and teachers' comprehensive development; and meanwhile it also conforms to the goal and demand for lifelong sports by Guidance Outline for Physical Curriculum Teaching in Colleges and Universities, which is adaptable to the development trend of physical education evaluation in colleges and universities with certain scientific and theoretical effect.

According to the evaluation contents and indicators of physical education, evaluation contents, indicators, weights and evaluation scale formed by empirical studies are generally objective, effective and operative compared to current evaluation methods for physical education in Jiangxi Medical College. It embodies the evaluation concept of promoting students' comprehensive development and teachers' constant improvement. It not only pays attention to students' physical abilities, but also values students' mental health with discovery and development of students' potentials in all aspects, including students' morality, personality and emotions. By this way, sports results are not the main evaluation means any more.

\section{REFERENCES}

[1] James F. Sallis Ph.D, Thomas L. McKenzie. Physical Education's Role in Public Health[J]. Research Quarterly for Exercise \& Sport, 1991, 62(2):124-137.

[2] Lee S, Burgeson C J, Spain C. Physical Education and Physical Activity: Results From the School Health Policies and Programs Study 2006[J]. Journal of School Health, 2007, 77(8):435-463.

[3] Kilby E L. National Association for Sport and Physical Education 1960-1985[J]. Journal of Physical Education Recreation \& Dance, 1985, 56(4):120-122.

[4] Rink J. Teaching physical education for learning[M]// Times Mirror/Mosby College Pub., 1985:92-96.

[5] Trudeau F, Shephard R J. Physical education, school physical activity, school sports and academic performance.[J]. International Journal of Behavioral Nutrition \& Physical Activity, 2008, 5(2):56-56.

[6] Bennett J P. Physical Education's Role in Public Health Responses[J]. Research Quarterly for Exercise \& Sport, 1991, 62(4):442-447.

[7] Sallis J F, Mckenzie T L. Physical education role in public health[J]. Research Quarterly for Exercise \& Sport, 1991, 62.

[8] Metzler M W. Instructional models for physical education[J] Instructional Models for Physical Education, 2005.

[9] Johnson B L, Nelson J K. Practical measurements for evaluation in physical education[M]// Burgess Pub. Co., 1979.

[10] Kirk D, Macdonald D. Situated learning in physical education[J]. Journal of Teaching in Physical Education, 1998 17(3):376-387.

[11] Marsh H W, Hey J, Roche L A, et al. Structure of Physical Self-Concept: Elite Athletes and Physical Education Students.[J]. Journal of Educational Psychology, 1997, 89(2):369-380.

[12] Rasberry C N, Lee S M, Robin L, et al. The association between school-based physical activity, including physical education, and academic performance: a systematic review of the literature.[J]. Preventive Medicine, 2011, 52(6):S10-S20. 